\title{
Improving Engagement In A Lecture Course By Increasing Relevance To Student Needs And Interests
}

William W. Arnold, Visiting Assistant Professor, Seaver College \& Pepperdine University, USA

\begin{abstract}
A modification in emphasis in an upper business course from a professor-centered approach to a student-centered focus demonstrated the use of possibilities to enrich a lecture course format to increase student engagement while also facilitating student readiness to enter the workforce. A proliferation of college teaching formats has emerged, including online learning, video teaching alternatives, and interactive learning outside the classroom. These rival formats offer new ways to engage students and ease them into future positions in organizations, yet the lecture format continues to be a choice preferred by many educational institutions. The transition to a course aligned with student needs and interests entailed numerous modifications in classroom conduct, curriculum, and student learning experiences. Certain changes appeared obvious along with other adjustments that, although profound, were subtle. This study identified factors associated with this transition along with their effects on students. Findings were based on input and evaluations by students. Three main factors were prominent in implementing the modifications: (a) augmenting the positioning of the professor as the unilateral classroom authority by adding the role of professor as agent of service to the students; (b) enriching content and assignments that immersed students in the course subjects, but often focused on the workplace environment; and (c) collecting initial input about student learning goals and requiring student feedback from each class meeting. Pre-post surveys completed by students assessed changes in their confidence on factors they associated with effectiveness in their careers.
\end{abstract}

Keywords: Lecture Course Format; College Student Engagement; College To Career, Student-Centered College Instruction, Student-Oriented Lecture Course

\section{INTRODUCTION}

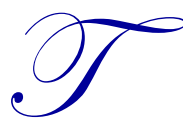

he unrelenting swish of change, inherent in the increasing reliance on digital capabilities, has disrupted accustomed practices of past decades. Educational institutions are forced to weigh alternate solutions that many students prefer over the traditional approaches of academic institutions. Educators are reaching for novel ways and new resources to keep pace with students who have become experts at assimilating information at internet speeds. With nimble minds and fleet fingers today's students are quick to access knowledge if and when they need it from the convenience of their pockets and pocketbooks, notably their phones and other digital devices.

This study touches on questions about the need for college students to be instilled with a broad foundation of theory and principles to meet future challenges in career and life. Numerous researchers (Cajiao \& Burke, 2016; Durant, Carlon, \& Downs, 2017; Gross-Loh, 2016; Jaschik, 2018; ) have raised concerns about whether the college lecture course format is a holdover from learning traditions of the past. The postured lecturer facing students who are poised to absorb information may be lessening student engagement and may not be as effective and efficient as newer instructional formats. Or, perhaps the old model of information flowing from lecturer to student needs can be beneficially altered to become student-focused and engaging. This article explores whether such a modification in orientation refocused on needs of students increases student engagement.

This research inquiry entailed collecting and examining student responses associated with a lecture course. The course intent was to retain the lecture format, but with the shift toward serving student interests and needs while also 
ingraining in students fundamental knowledge of topics included in an upper division business course on management theory and practice.

\section{LITERATURE REVIEW}

\section{The Lecture Class Format}

A review of research findings on classroom pedagogy indicated well-researched arguments for replacing passive learning, a term grafted onto the lecture format, with a plethora of teaching approaches associated with "active" learning. Rigorous studies have shown advantages of numerous teaching methods over the lecture class method. These alternative formats offer new learning experiences, engage students in activities, and empower students in courses. The lecture format choice nonetheless has a core following that ensures its continuing support, at least for a time (Durant et al, 2017; Jaschik, 2018). Reporting on an observational study of college science teaching, Jaschik (2018) stated that most classrooms (55\%) spent the majority of time on lecturing. A second group (27\%) interspersed interactivity with lecturing, and only the smallest group of classes (18\%) emphasized high student participation using group work and discussions.

Charlton (2006), based on 18 years of lecturing students in science courses, defended the class lecture as an effective teaching method. Differentiating lectures from solitary learning by reading and learning from electronic media which he claims can be distracting, the author offered the rationale that lectures engage human faculties and meet social needs. Charlton (2006) further developed his arguments on behalf of lectures based on their formality, the spontaneity of spoken experience, and social aspects of the class. Charlton (2006) claims the succession of lectures over the time builds trust between lecturer and students, which is conducive to learning. In addition, he is a proponent of notetaking which encourages deep processing that requires students to understand, abbreviate, and re-structure information. This process essentially converts the passive experience of listening into an active learning experience (Charlton, 2006).

Factors that appear to be blocking change from the lecture method include lack of awareness of viable instructional alternatives, lack of confidence in attempting a new approach, tendency to teach the way the instructor was taught, and long-held beliefs about instructional practices (Jaschik, 2018). Jaschik (2018) added that rationale called forth to avoid varying from the lecture format includes class sizes that are too large and classroom layouts that are not set up to allow group discussions.

In an article that traced the lecture format from its roots in antiquity, Gross-Loh (2016) referred to research that found superior results due to active learning compared to the lecture method, raising the point, however, of whether this conclusion was attributable to lecturing as a teaching method or to the inadequate presentation skills of manycollege instructors. The phrase active learning has become synonymous among educators with experiential learning; the flipped classroom, referring to student study outside of class time via videos, text; and other teaching paradigms that shift the class dynamic toward student interaction (Gross-Loh, 2016). A remaining question concerns whether the lecture format has potential to be transformed into an enlivening experience for students that engages their attention and achieves learning results at parity with active learning as the term has become known (Gross-Loh, 2016).

\section{Digital Generation: Conditioning and Expectations}

Of the three generations now spanning the workforce, technology-savvy Millennials and the newest generation, Gen Zers, dominate by numbers, with Baby Boomers waning in percentage of employees (Williams, 2015). Based on data from the U.S. Bureau of Labor Statistics and analysis by the Pew Research Center, an estimated 56 million Millennials (born between 1981 and 1996) now constitute 35\% of all workers (Fry, 2018). Gen Zers, born after 1996, are the first generation to be raised with smart phones. Individuals in the technology-intensive era have become accustomed to taking in information instantaneously and moving on to other interests in rapid succession (Williams, 2015), a phenomenon that has changed the ways of learning and working.

Millennials have been typified as "tech savvy, enlightened culturally, and wide open to possibility" by Vegar Wiik, Executive Education Director, Florida Atlantic University College of Business (n.d., p. 1). They have influenced business schools to adopt devices, software, and communication capabilities now possible with digital technology. 
Students have new options for learning, such as watching a lecture on smart phones and spreading their listening time over 10 to 15 -minute segments. In many cases colleges are eager to adopt digital learning aids but deterred by the need to integrate new instructional configurations into the college catalog. In a survey finding by PayScale and Future Workplace Katie Bardaro of PayScale reinforced the reality that "It takes time to build a curriculum and obtain an expert who can teach [new technology applications], and the technologies are just changing too rapidly" (para. 10).

Technology detractors have been vocal in tamping down enthusiasm about learning in a digital age. Carr (2017) asserted that accessing information so conveniently appears to erode the mental task of remembering, as people feel they can look up anything they need. Several university-based experiments found that students' test performances, memory, and attention spans diminished by the mere proximity of their screens, even if they were not looking at them. A claim has been made that: "As the brain grows dependent on the technology... the intellect weakens" (Carr, 2017, p. C1-2). The author pointed to scientific evidence that the brain monitors as well as thinks and is quick to be distracted by all stimuli (Carr, 2017). Pedersen (2018), referring to the barrage of information that presently confronts students and knowledge workers, emphasized the need to develop focusing as a skill, stating that developing agile and disciplined thinking abilities can help in assimilating and analyzing large amounts of input that can otherwise lead to overload and cognitive processing paralysis.

\section{Employers' Perspectives: Preparation Expected of Students}

The U.S. economy and its workforce have evolved from the agricultural sector requiring physical strength, to mass production requiring repetitive tasks, and to information-based products and services requiring specialized knowledge. New requirements have emerged related to added skillsets, information processing, and the need for people to work interdependently. Organizations that compete for consumer and business attention increasingly rely on employees' knowledge plus their soft skills including teamwork, communication, and interpersonal skills (Ritter, Small, Mortimer, \& Doll, 2018).

The Council for Adult and Experiential Learning (2011) stated that identification of competencies, that is, what a worker should know and be able to do, can be valuable in selecting job candidates and predicting their success in careers. The National Association of Colleges and Employers (NACE) (n.d.) spearheaded an extensive initiative to clarify employers' requirements for work-ready college graduates. The Association's definition of career readiness, which was built on research, analysis, and consensus, is: Career readiness is the attainment and demonstration of requisite competencies that broadly prepare college graduates for a successful transition into the workplace. NACE (n.d.) identified eight competencies associated with career readiness:

1. Critical thinking/problem solving

2. Oral/written communication

3. Teamwork/collaboration

4. Digital technology

5. Leadership

6. Professionalism/work ethic

7. Career management

8. Global/intercultural fluency

Having a formal definition of career readiness is a rallying force for developing goals and programs that can help reduce the gap between students' college preparation and their entry into the workplace. Competency statements can be used for job descriptions, tests of skill proficiency during the hiring process, and identification of skills needed in the workforce. They may be incorporated into training materials, performance assessments, and individual professional development plans (Council for Adult and Experiential Learning, 2011).

Results from studies of new college graduates and employers conducted by the Association of American Colleges and Universities (AACU) emphasized that employers prefer hires from college to have a range of knowledge plus skills specific to work-related areas (Jaschik, 2015). Thirty percent of employers indicated college graduates were less than well prepared on capabilities contributing to workplace success, namely, applying knowledge and skills in real-world settings, critical thinking skills, and written and oral communication skills (Jaschick, 2015). 
Hora (2017) related experiences spread over two years of interviewing 145 people in 17 educational institutions and 52 companies, all within the State of Wisconsin, emphasizing contacts within manufacturing and biotechnology.

Employers valued the soft skill competencies of communication, teamwork, and critical thinking, but they also needed employees who could communicate in a specific discipline or industry context, such as a science lab, or a welding repair shop. The author concluded that career competencies are "best thought of as a holistic repertoire of skill sets linked to specific fields" (Hora, 2017, p. 3).

\section{The Student and College Perspective: Preparing Students for Careers}

A study by the National Association of Colleges and Employers (NACE) (2018a) compared ratings by 200 employers and more than 4,000 graduating seniors on their perceptions of proficiency related to career readiness competencies (see the NACE definition of competencies in previous section). Students rated themselves higher than employers rated students on proficiency for 7 of 8 competencies. The only competency on which employers rated students higher was digital technology with ratings of $66 \%$ by employers and $60 \%$ by students. The widest disparity in ratings was professionalism and work ethic, where employers rated students $43 \%$ and students rated themselves $89 \%$ (NACE, 2018).

Hora (2017) urged that "innovation and change needs to happen around a core, foundational commitment to students' well-being over the long term" (p. 6). The author recommended that educators and employers build a skills infrastructure for students that instills contemporary competencies and a foundation for life-long learning. Research by Gaertner, Conley, and Stoltz (2016), emphasized a need for assessment tools and models that identify student strengths and weaknesses toward career readiness, combined with links to resources and solutions students can act on. The authors commented that career readiness and life outcomes are influenced by a cluster of factors that are difficult to change, such as socioeconomic circumstances, past academic achievement, and quality of education in lower grades. The implication is to focus on factors that can be influenced to improve career readiness and outcomes. The authors recommended taking into consideration the students' goals, circumstances, and attributes to develop a plan that improves the likelihood of success, including using the student's strengths to compensate for their weaknesses (Gaertner et al., 2016).

Barnes \& Noble College (2015) conducted a study of 3,000 students in colleges in 44 states that indicated students tend to delay their preparation in college as they transition toward careers. Further, students appear to focus more on their job searching tasks than on improving the skills that would contribute to their success on the job. To bridge from college to work, one program (NACE, 2018b) offered a workshop that guided students in developing their 90- day onboarding plan. Key elements were:

1. developing relationships with managers, teams, peers, and other departments

2. sorting out the real culture and sub-cultures of the organization

3. discussing goal setting and expectations

4. building support systems internally and outside the organization

5. achieving early success by completing a meaningful project

In making a case for collaboration between business and education, a report by the U.S. Chamber of Commerce Foundation (2017) pointed out that waiting to improve an employee's skills until after employment is expensive for employers. Six successful business and education partnering programs, described in a report by the U.S. Chamber of Commerce Foundation (2017), demonstrated that "Businesses recognize the critical need for soft skills and are working hard in their communities to help students obtain the skills they need to succeed in the jobs of tomorrow," according to Cheryl Oldham, Senior Vice President of the Foundation's Center for Education and Workforce (U.S. Chamber of Commerce Foundation, 2017, p. 5).

The present siloed structure in academia can thwart efforts of departments to take effective steps toward building training for career readiness into their curricula. Challenges educators face include funding and operating mandates at local, state, and federal levels. In addition, colleges are held accountable by test performance and other metrics, as well as by the need for students to score well on graduate admissions exams (U.S. Chamber of Commerce Foundation, 2017). 


\section{Developing Students' Soft Skills}

In advising students for future outcomes, Gaertner et al. (2016) assessed the labor market as “...beginning to care a bit less out what students know... and a bit more about how they are able to continue to learn and to apply knowledge in novel and non-routine ways in real-world settings" (p. 1). Referring to new hires from colleges, a Chamber of Commerce member in Nashville, stated "As long as they are critically thinking, problem solving, and have the right attitude... we will train them on the technology they need training on, that's not an issue" (Johnson, 2016, p. 1). In a survey of corporate recruiters a candidate's ability to participate in and build strong teams ranked in the top 3 of 12 prized performance traits. Recruiters looked for interpersonal abilities that suggest harmonious and productive interactions (Graduate Management Admission Council, 2016).

Soft skills in past times were often dismissed as fixed personality traits, but evidence is abundantly available that soft skills can be taught and acquired throughout an individual's life (Youth Power, 2017). Research attention is now shifting toward understanding how youth can be assisted in developing these skills (Youth Power, 2017). Gaertner et al. (2016) recommended development of assessment tools that yield understanding of readiness to succeed along with areas in need of improvement that are linked to resources students may access to strengthen their preparation.

Ambiguity among soft skills appears to be the rule rather than the exception. For example, oral communication skills can be differentiated as presenting, listening, and conversing, as discussed in a report on learning goals of U.S. undergraduate business programs accredited by the Association to Advance Collegiate Schools of Business (Brink \& Costigan, 2015). In terms of workforce development, seven skills have gained widespread acceptance, namely, positive self-concept, self-control, higher order thinking skills, social skills, communication, empathy, and goal orientation (Youth Power, 2017). The identification of soft skills coalesces around several factors, as indicated by the skills listed in the report by the U.S. Chamber of Commerce Foundation (2017):
1. Teamwork and collaboration
2. Leadership
3. Problem solving and critical thinking
4. Work ethic and persistence
5. Organization Creativity
6. Interpersonal communication
7. Relationships (conflict resolution)

An analysis by Indeed.com, a leading source of job openings, showed that mentions for critical thinking in job postings doubled between 2009 and 2017 (Reed, 2018). Critical thinking encourages keeping an open mind and reviewing a variety of viewpoints and solutions (Reed 2018). Results from the College Learning Assessment Plus (CLA+), an annual test given at 200 colleges in the U.S. to measure improvement in students' thinking capabilities, indicated the majority of students that took the test showed measurable progress in critical thinking. On the negative side, at more than $50 \%$ of test-taking schools $33 \%$ of the seniors could not make a cohesive argument, assess the quality of evidence in a document, or interpret data in a table (Belkin, 2017).

Evaluating a situation, collecting information, weighing alternatives, and deciding on the best option may draw on troubleshooting, critical thinking, and problem solving skills. In evaluating assessment tools that measure student readiness Gaertner et al. (2016) identified adversity, defined as one's capacity to handle and respond to challenge, as a factor that influences an individual's capacity to flourish and achieve their potential. The authors found that students who rated high in ability to overcome adversity also scored high in performance, resilience, productivity, optimism, quality of life, health, capacity, and innovation. Gaertner et al. (2016)delved into the characteristic of grit, which they defined as one's capacity to "dig deep, to do whatever it takes, and especially to sacrifice, suffer, stumble, and struggle in pursuit of worthy goals" (p. 16). Associated terms are resilience, instinct, tenacity, perseverance, and fortitude. The authors suggested that job candidates who demonstrate grit also have the potential to grow into successful employees and leaders (Gaertner et al.).

In the Millennial Mindset Report (Barnes \& Noble College, 2015), students acknowledged that skills such as communication and teamwork are important, but were uncertain about how to develop these skills. Among colleges 
addressing the career readiness gap Excelsior College (Shih, 2017) has set preparing graduates for careers as a top priority. Maribeth Gunner, Director of Career Services, expressed the need: "Recruiters and employers rarely make the hiring decision solely based on whether the person knows how to do the job, they also want people who know how to handle themselves at work and relate to customers and colleagues" (Shih, 2017, p. 2).

Six guiding principles for effective soft skills development programs have been offered in the report by Youth Power (2017):

1. Experiential learning that includes challenge, experience, practice, and reflection

2. Learning and practicing skills in combination rather than in isolation

3. Developing strong relationships among adults and peers

4. Supportive staff practices including modeling and reinforcement

5. Safe, supportive, and enriching environment

6. Integration across learning contexts (Youth Power, 2017)

These principles combined with others provide a useful framework for examining possibilities to improve student learning experiences across the spectrum of learning formats and environments.

\section{Engagement Drivers: Need and Relevance}

In summarizing the literature review, the lecture method, so closely associated with a college education, has loosened its clench and is on the decline as the predominant instructional method, at least among choices in developing new curricula and courses that are being developed for new media and a variety of delivery channels. Methods that rival the lecture format are claimed to achieve superior learning effectiveness, especially when those alternatives offer active learning experiences. Pressures to replace lectures are apparent from post-Baby Boomer generations for whom digital communication has become the preferred way to receive information. Employers prefer to hire college graduates who are work-ready and show promise of high potential to become leaders in their organizations. College graduates often fall short of meeting employers' expectations, especially in the areas of soft skills that allow students to enter the workforce, fit in, and start contributing alongside their seasoned colleagues and company managements.

This study demonstrated the possibility of strengthening the lecture method by emphasizing human-centered approaches being adopted in many organizations, skewing class time toward instilling insights into the operating practices in the real world of organizations, and assigning tasks and projects that assist students in preparing for their transition from college to career. The following Figure 1 summarizes the variety of student needs addressed throughout the course along with the premise that engagement intensifies as a function of relevance to student needs. 
Figure 1. Improving student engagement by increasing relevance to student needs and interests

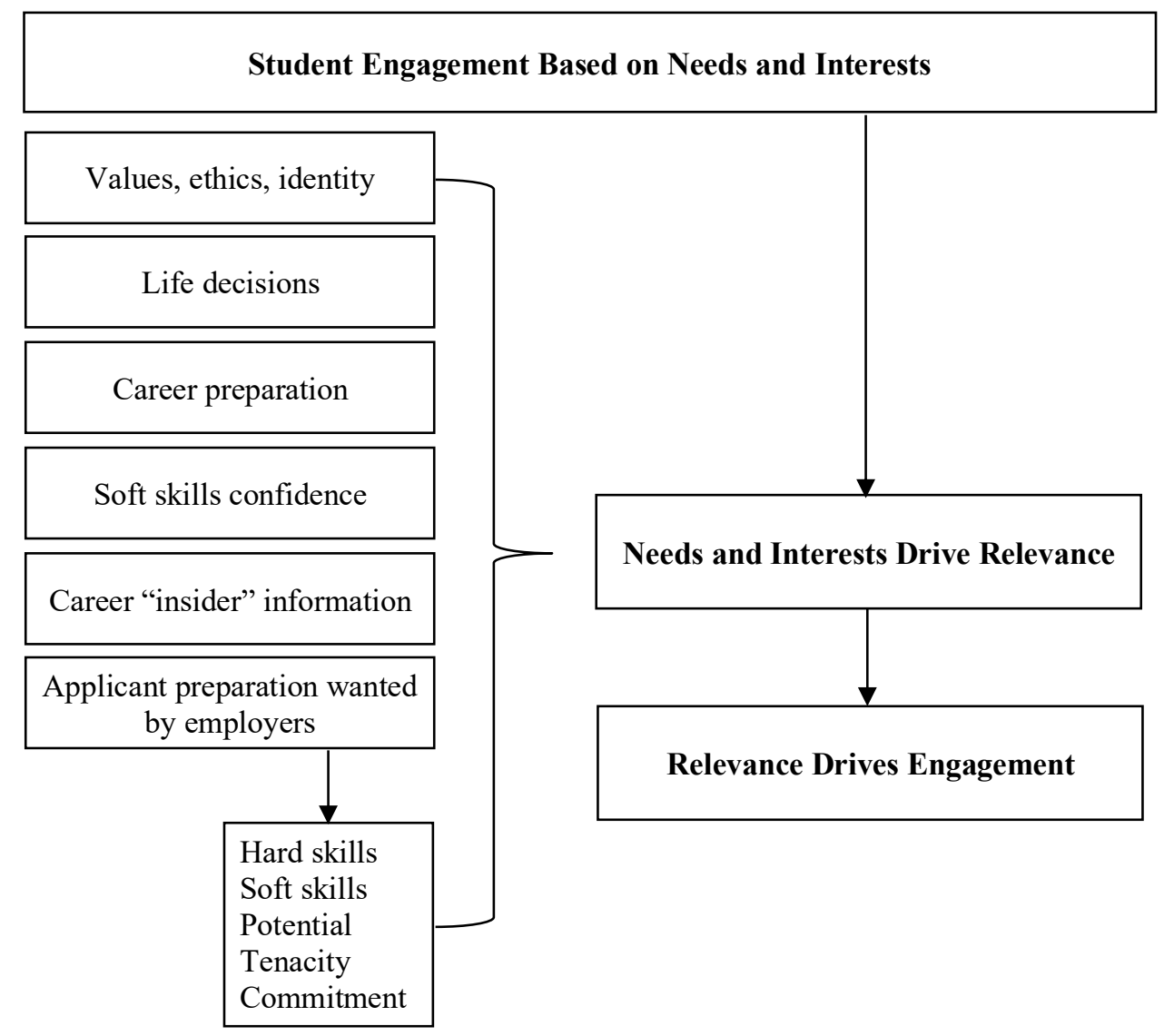

\section{A LECTURE COURSE ADJUSTED TO MEET STUDENT NEEDS}

The Professor has taught upper division college courses on management, strategy, leadership, and organizational behavior since 2004 and has taught the course on Management Theory and Practice at Seaver College Business Division, Pepperdine University, since 2010. He taught the course, which was the subject of this study, in the fall of 2017. The 36 students were divided into two sections of 18 students each that met twice weekly for 12 weeks.

Following is the Seaver College Course Catalog description of the Management Theory and Practice course (B.A. 352):

A study of the basic concepts of management built on an understanding of organizational theory. Equal emphasis is placed on theoretical and operational aspects of the manager's role in organizations. The course deals with management issues: planning and controlling, structuring and staffing, directing and leading, and business and society with a special emphasis on managerial ethics (Pepperdine University, 2017, p. 136).

As an informed observer of students over the past 7 years, the Professor has been alert to changes over the years in student readiness for transitioning beyond graduation, especially in students' increased interest in preparing for careers. Compared to students in earlier years, the students in the fall 2017 were likely to:

- Be more motivated concerning their career goals

- Be more purposeful and focused about career success

- Start earlier in the career placement process

- Be more resourceful about getting career help 
- Access technology more extensively

- Screen companies and jobs to match interests and values

- Plan to seek advanced business degrees

- Prefer companies that offer tuition assistance

- Apply to the top 4 CPA firms if they were accounting majors

The Professor orientated and structured the course toward student needs, developing a configuration that blended instruction in required course subjects with assignments related to students' needs. The course was enriched with assigned tasks that gave students insights into what it is like to work in an organization. The Professor shared his experiences in leading organizations, which reinforced and amplified principles and practices found in organizations, teams, and management roles. In addition to complementing the textbook content, student assignments were designed to prepare students to enter the workforce and pursue productive careers.

\section{Composition of the Class}

The demographic composition of students in the class corresponded to typical patterns and diversity of the Seaver College student body and of previous classes in Management Theory and Practice. The course is available to upper division students. Combining the two sections totaling 36 students, 21 were seniors, 13 juniors, and 2 were sophomores. Major fields of study fell within a cluster of business functions that included: Business Administration, Economics, Finance, Marketing, Non-Profit Management, Public Relations, Advertising, Sports Management, Communications, and International Business. The gender ratio of the class was $60 \%$ women and $40 \%$ men. Several students had received their high school diplomas in countries outside the United States. Most students had accumulated work experience and several were employed while they were taking the course. Racial and ethnic mix assured diverse perspectives among the students.

\section{Students Career Plans Following Graduation}

The class post-survey administered at semester end included a check-off statement "In the 12 months following completion of my undergraduate degree, my predominant role(s) will be:" Students were requested to check off their first and second choices. Their expectations are shown in the following Table 1.

Table 1. Student Projected Endeavors Following Graduation

\begin{tabular}{l|c|c}
\hline \multicolumn{1}{c}{ Predominant Role(s) } & Number & Percent \\
\hline Work at Profit or Non-Profit & 28 & $42 \%$ \\
\hline Pursue Graduate Study & 23 & 35 \\
\hline Travel, Study Languages & 6 & 9 \\
\hline Start Own Enterprise & 5 & 8 \\
\hline Work for Government or Family Business & 4 & 6 \\
\hline Total & 66 & $100 \%$ \\
\hline
\end{tabular}

Note: $\mathrm{N}=66$ responses from 35 students. Source: Student survey responses.

\section{Conduct of the Class}

In conducting the class meetings, the Professor modeled the role of Manager, simulating the productivity of a work environment. In several ways such as class structure, agenda, focus questions, and business-like pacing the Professor modeled professional demeanors and behavior. Seeing soft skills in action demonstrates their effects and provides students with lessons to help improve their soft skills (U.S. Chamber of Commerce Foundation, 2017; Youth Power, 2017).

The Professor maintained a set schedule of office hours. Additionally, he was available before class meetings and scheduled meetings with students outside of office hours as needed. His accessibility mirrored contemporary practices in many organizations in which a manager becomes the coach and facilitator of the employees' achievement (What the best managers do..., (2018). The Professor encouraged open communication including contact from students by 
phone, texting, and email. He gave each student his business card and invited students to get in touch any time he could contribute to their progress.

The Professor also projected his enthusiasm for teaching. He demonstrated a caring attitude and regard for the students' personal and professional interests. According to Youth Power (2017) effective learning depends on setting up caring, supportive relationships in environments students perceive as safe. The learning atmosphere, the authors recommended includes relationships that:

1. express care

2. challenge growth

3. provide support

4. share power and treat students with respect

5. expand possibilities for students

The Professor's interactions with students aligned with the Youth Power report guidelines. In addition, the Professor applied his knowledge of human behavior and modeled authenticity in relationships, thereby gaining relationships of trust with the students, a precursor of engagement.

\section{The Class Meeting Agenda}

Class meetings were structured and followed a similar pattern at each meeting. The Professor opened the door to the classroom at 7:15 a.m. to prepare for the 8:00 a.m. class start time. Students were welcome to come in early and the Professor was available to respond to questions and engage in discussion. The Professor placed "Today's Agenda" on the board as well as the agenda for the next class. In addition, the Professor placed three questions on the board that drew attention to the topics of the day's class. Lang (2016), based on the science of learning, emphasized opening class time with questions, asserting that that two to three questions at the beginning of class and returning to these at the end reinforce learning and convey purpose. The Professor also placed on the table at each class meeting an article and blank 4x6 inch cards on which students were to write their response to the statement, "My most important management learning from today's class was:" (students filled in)

At 8:00 a.m. the class began. The Professor directed the class to consider the three questions on the board. He then introduced key points of the article of the day and often reinforced the points by relating an example from his experience as a corporate executive. By 8:20 the Professor began to review the academic subjects of the day and lectured on topics from the class textbook, again interspersing his career stories or a point from the article. At 9:10 the processor referred back to the three questions placed on the board earlier. After a few minutes of discussion and questions, the students finished writing their comments on the "most important management learning cards." The class was dismissed by 9:20.

\section{Basic and Enrichment Features}

\section{Text}

The class lectures covered the content of the 14 chapters organized into 5 parts of the assigned text, Understanding Management (Daft \& Marcic, 2015). The textbook authors have published nine editions of the text, each time updating it with new topics and information that reflect changes in management thinking and practice. Table 2 shows the 5 parts of the textbook and major subjects. 
Table 2. Textbook Parts, and Chapter Subjects of Understanding Management (Daft \& Marcic, 2015)

\begin{tabular}{|c|c|c|c|c|}
\hline $\begin{array}{c}\text { Part 1 } \\
\text { Introduction to } \\
\text { Management }\end{array}$ & $\begin{array}{c}\text { Part } 2 \\
\text { Environment of } \\
\text { Management }\end{array}$ & $\begin{array}{c}\text { Part } 3 \\
\text { Planning }\end{array}$ & $\begin{array}{c}\text { Part } 4 \\
\text { Organizing }\end{array}$ & $\begin{array}{c}\text { Part } 5 \\
\text { Leading }\end{array}$ \\
\hline $\begin{array}{l}\text { - Innovative } \\
\text { Management for a } \\
\text { Changing World }\end{array}$ & $\begin{array}{l}\text { - Organization Culture } \\
\text { - Global Environment } \\
\text { - Ethical and Social } \\
\text { Responsibility }\end{array}$ & $\begin{array}{l}\text { - Planning and Goal } \\
\text { Setting } \\
\text { - Decision Making }\end{array}$ & $\begin{array}{l}\text { - Adaptive } \\
\text { Organizations } \\
\text { - Change and } \\
\text { Innovation } \\
\text { - Human Resources, } \\
\text { Diversity }\end{array}$ & $\begin{array}{l}\text { - Individual Behavior } \\
\text { - Leadership } \\
\text { - Motivating } \\
\text { Employees } \\
\text { - Managing } \\
\text { Communication } \\
\text { - Team Performance }\end{array}$ \\
\hline
\end{tabular}

Study Guide

The study guide, an abbreviated outline based on the textbook, linked key academic concepts to page numbers in the book. Students were allowed to use the study guide while taking their exams.

Articles

The articles provided to students at each class complemented the textbook subjects with focus on careers, job placement, inspiring life accounts, interviews with accomplished executives and founders, and people who have overcome obstacles. The Professor selected articles from business journals, magazines, and newspapers such as the Wall Street Journal. The salient points of each article were discussed at the beginning of class. Students retained the articles for reading later. Examples of articles selected for review at class meetings were:

- Breaking out of shyness: The story of Thomas Lynch, a sales support lead, and his breakthrough into management that demonstrated triumph over the frustration of a qualified professional who felt he was ready for a management position. Lynch, a self-described introvert, was good at what he did but had a reserved demeanor and blended in when it would have been to his advantage to stand out. Acting on advice from a career coach, Lynch began to be proactive in reaching out to make his strengths clear to others. He took risks more readily, spoke up more often in meetings, asked his supervisors what he could do to gain more responsibility. Reflecting on a recent extra assignment, one executive now described Lynch as a "difference maker." Lynch became purpose-oriented rather than advancement- driven, and the benefits that started appearing in his professional career also became evident in his family and community life (Shellenbarger, 2014).

- The value of asking questions: Adam Bryant, the New York Times columnist, interviewed Dottie Mattison for an article "Talk Less, but Ask 'Why' More" (Bryant, 2016). Mattison, CEO of Gracious Home New York, honed her leadership skills working for a large consumer brander and her own venture. As her leadership style evolved, she indicated she talks less now and asks questions more. Her advice is to ask "why," and this stems from her practice of following up a first question by asking successive "whys" to find the truth. She may put forth her "why" questions a total of six times, all following responses to her first question.

- Priorities and tips for career success: A roundup of CEOs on the topic of habits that impede management success (Thibodeaux, 2018), offered advice that may not be intuitive. Just out of college, for example, the job seeker is advised that putting money first over learning could lead to missed opportunities to achieve earning potential in mid-career. Being too close to a project can hurt a small business. Thibodeaux offered other advice such as not trying to blend in when standing out is more appropriate and not holding back ideas by rationalizing that they might not be received enthusiastically.

Stories

As stated by Bledow, Carette, Kuhnel, \& Bister (2017), stories are a way of enriching learning by introducing the lessons of other people's experiences. Chip Heath and Dan Heath (2008), writing on why stories stick with people, believe that stories simulate situations and convey knowledge about how to conduct themselves in real situations. They also inspire and provide motivation. Adding knowledge, action, and credibility to a story causes people to 
commit to the idea. Further, adding an emotional twist prompts caring. Then add drama, and it is clear to see why stories can be memorable and have impact (Heath \& Heath, 2008).

Bledow et al. (2017) studied the motivating force of stories, focusing their perspective on stories of failure. Their research found that negative experiences could be more effective than examples of positive experiences. Based on findings in psychological theory, the authors stated that negative events prompt people to engage in elaborated thought and may motivate generating new ideas in the attempt to find alternate solutions with higher potential for success (Bledow et al., 2017).

The Professor offered stories from his experience to emphasize points and share the reality of organization practices. The Professor's core career in executive leadership of several major medical centers included national healthcare networks. Holding positions as CEO, COO, and Chief Strategy Officer, his signature achievements focused on changing organization structures, transforming communications toward openness with employees, and improving profitability by empowering managers with authority to take actions that benefited the organization, patients, and the public. At several healthcare institutions he was engaged by an underperforming organization and given wide latitude to launch changes to improve performance. Three examples were:

- Accountability and ownership: After being introduced in a new executive position at a major healthcare institution, the Professor met with the managers. Among the Professor's agenda was a review of the recent profit and loss statements. Noticing the blank stares when he began discussing financial issues, he stopped to learn the managers' familiarity with the numbers. Clearly, the managers had never been given financial statements and were not informed about facts or figures related to performance of their departments. At the next managers' meeting the Professor distributed the monthly balance sheet. Alarmed at this, the Chief Financial Officer said, "You can't do that." The Professor said, "Yes, I can. That's a key measure of the work of these managers." As the managers reviewed the numbers, they could see directly the effects of decisions and practices within their departments. The now fully informed managers became full owners and partners in the organization. Taking charge, they were able to improve financial performance.

- Releasing suppressed energy: The Professor described coming into a healthcare institution that was very traditional with a rigid a chain of command, complete with top-down communication flows that reached the employees considerably after news occurred or policies changed, and sometimes not at all. The Professor took emphatic action to clarify that changes were imminent. The Professor had the door of his office removed and had it hung upside down in the lobby area outside his executive office row. This action also signaled a new receptivity to sharing information more openly. He brought a coffee maker into his office and invited people to stop by. He displayed photos of his family to humanize his office. At lunch in the cafeteria he sat at tables of employees over lunch. Managers began to feel more comfortable and became more open in their communications with employees. The stuffy, frozen environment thawed and new energy emerged as employees and managers also felt released to share their ideas and new thinking to solve problems.

- Facilitating potential: A critical leverage point in achieving profitability of healthcare institutions is to reduce the accounts receivable aging. The Professor discovered the receivables at medical center he had joined had stretched to 72 days. He visited the department, which was on the lowest level of the facility in a windowless basement. Surveying the dismal environment, he directed a switch to relocate the department to the upper floor where executive offices were and moved the executives to the basement. He also gave the receivables staff discretion to reconfigure their new space. In addition, technology was upgraded with the latest software, and employees were encouraged to propose solutions that would increase the effectiveness of the department. The employees became owners in the process of finding solutions. They were fully engaged and became more innovative in finding ways to improve their performance. Within 7 months receivables dropped from 72 days to 43 days, drastically increasing revenue per patient day. 


\section{Exams}

The students took four exams during the semester, each covering three to four of 14 chapters in the assigned textbook (Daft \& Marcic, 2015). The final exam over the ending three chapters was administered at the last class. Each exam had seven questions. Students were allowed to refer to their Study Guides during exams. Student responses were restricted to short answers, for example "state three key ideas," "respond in a sentence of 10 words or less," or "provide two key learnings."

Although the exams tested students' knowledge of the textbook content, the Professor introduced one question to further develop the students' critical thinking skills. In contrast to the short-answer questions, one question in each exam required students to write an essay based on an article they read during the exam period. The set-up for each essay question followed a similar pattern:

Step 1: State three (for example) learnings about a designated topic (for example) from the text. The Study Guide number was supplied for the students to use during the exam.

Step 2: Now connect each stated learning to an example from the provided article. Students were instructed to complete their essay in no more than three pages of their test booklet, which allowed for an essay of 250 to 300 words.

The exam articles of five to six pages focused on topics such as leadership, a new process being adopted by organizations, and an in-depth profile of a CEO. Three examples of exam articles were:

1. "Nadella Rewrites Microsoft's Code," in Fast Company (McCracken (2017). A theme of the article was Nadella's leadership, which changed the company's culture.

2. "HR Goes Agile," in Harvard Business Review (Cappelli \& Tavis, 2018). Application of Agile techniques across key functions of an organization including adopting team approaches used in technology organizations,

3. "Turning Potential into Success: The Missing Link in Leadership Development," in Harvard Business Review (Fernandez-Araoz, Roscoe, \& Aramaki, 2017). The authors proposed 4 steps to prepare leaders, ending with coaching and opportunities to strengthen competencies.

Feedback from students indicated the articles were practical and that linking important principles to issues in the articles helped them develop their critical thinking abilities.

\section{Cards}

The rationale for requesting students at each class meeting to write on cards to complete the sentence "My most important management learning today was:___ (students filled in) " has roots in learning theories and practices that have shown the value of reflection in developing critical thinking abilities requiring analysis and synthetization that reinforce learned content for later recollection (Cajiao \& Burke, 2016) The authors' study of 246 students in a university-based leadership course explored lecture-only instruction plus three additional pedagogical formats that added reflection, dialogue, and experiential exercises. Reflection was investigated as a process of reexamining how experiential learning promotes deeper understanding of concepts. At the end of activities students were asked what they had learned about the content. The authors concluded that reflection can "produce meaningful improvements in students' learning behaviors..." (Cajiao \& Burke, 2016, p. 521). In a study by Youth Power (2017) the authors recommended coupling engaged learning with reflection, defined as meaning-making, as well as compelling students to describe what they understood, evaluate their performance or choice, and connect their experience to what they already knew.

\section{Final Class Paper}

Students were instructed to choose a high performing organization related to their career interests. In addition students were to select five academic topics of personal and professional relevance to provide the focus for the final project. 
Length of the paper was limited to 10 pages including references. Examples of topic themes could be human capital, leadership, social responsibility, technology, and culture. The students analyzed the chosen organization and evaluated it in terms of the themes. The final paper assignment was designed to integrate topics studied during the course that were meaningful to the students and to give them experience in analyzing a prospective employer.

Students were encouraged to interview one or more people who held management roles in the organization.

\section{METHODOLOGY}

\section{Mixed Methods Research Design}

Multiple measurements were collected directly from students throughout the course. Data from students captured their voices from varied perspectives including time, context, and data input forms (Creswell, 2014). This mixed method design provided data that allowed triangulation, corroboration, and contrast that afforded a depth of analysis and enriched insights. The following summary shows the data collection sources used in this study:

Expectations of Professor for a great class: Open-ended essay assignment at beginning of course

4x6 inch cards - My most important management learning today: Students completed at each class meeting, a total of 24 classes

Pre- and Post-Survey: Administered the 4 th $^{\mathrm{d}}$ and $24^{\text {th }}$ class meetings

Q1. Actions critical to managerial effectiveness: List of 13 actions rated on 5-point scale

Q2. Competencies most important to effectiveness: List of 6 competencies rated on 5-point scale

Q3. Confidence about effectiveness related to competencies: List of 6 competencies rated on 5-point scale

Post-survey only: Added open-ended question, "In what ways has your confidence related to (the competency) changed due to what you have learned in this course?")

Q4. 3 aspects of management most important to effectiveness: Open-ended, limited to 3 words or short phrases Pre survey: ..." will be most important." Post survey: ..." that I have learned in the course."

Q5. Activities during class that engaged me the most: Post survey only Q6. Activities during class that engaged me the least: Post survey only

Q7. Following my undergraduate degree, my predominant role(s) will be: Post survey only: Check-off from7 options

\section{Qualitative Data Analysis}

The methods used in analyzing qualitative data followed well established procedures used in data reduction in the social sciences and required both deductive and inductive approaches (Creswell, 2014). Several questions elicited short responses: for example, "The 3 aspects of management I have learned in the course that will be most important to my management effectiveness are." The responses were entered electronically into spreadsheets and grouped into categories. Within each category, responses were alphabetized and adjusted for word-ending or tense variations and synonyms. In instances of ambiguity, evaluation of the intent or meaning served to associate it with an established category. Responses judged to be spurious or meaningless were deleted. Frequency counts of items within groups were then calculated, and groups were ranked based on frequency counts. Percentages were calculated to show distribution of categories and to aid in displaying summary data in tables and figures.

One open-ended question yielded more extensive responses and generated a large volume of data. The students completed their responses to the question on $4 \times$ x 6-inch cards at each class meeting. Data provided to the question, "What was the most important management learning from class today?", followed the procedure described earlier but with added steps. Responses were entered into spreadsheets from which the data were reduced to "essence phrases" that captured the core meaning of each response. From this step a further reduction was carried that involved associating the essence phrases with a textbook chapter subject on a "best fit" basis. 


\section{Quantitative Data Analysis, Survey Questions}

Extensive research conducted at the Harvard Graduate School of Education, as reported by Gehlbach and Brinkworth (2011) and later in collaboration with Panorama Education (2015), advanced the use of survey scales. The Gehlbach and Brinkworth research was undertaken to improve teaching effectiveness by considering the voices of students. The suggested survey tool advances were a product of large scale, iterative testing and determination of validity that built upon the typically used Likert scales (response choices: no, maybe, neutral, probably, yes).

Integrating these advances into survey design emphasized:

1. wording survey items as questions rather than statements

2. limiting questions to one idea at a time

3. using 5 or more response options

4. showing verbal labels

5. favoring positive language to avoid confusion caused by "reverse scoring"

The pre- and post-survey and question-response scales prepared for this study conformed to the recommendations made in the Panorama Education (2015) User Guide: Panorama Student Survey.

Data from responses to scale options ( 1 through 5) were submitted to $t$-tests, as appropriate for samples of more than 30 subjects. In addition to testing statistically (pre-post) for significant differences, frequency counts and ranking of response categories were determined.

\section{ANALYSIS AND RESULTS}

\section{Student Expectations of Professor for a Great Class}

On the first day class for each of the two sections of 18 students, the Professor requested the students to write an essay to complete the phrase "Expectations of [my Professor] for a great class are:" (students filled in)

The Professor's primary intention was to generate a baseline indication that would identify student needs. An ancillary intention was to invite the students to express their voices about what, in their perceptions, would constitute a great class.

In total, 82 data points were mentioned by the 36 students. Response categories were developed from analysis of student responses. The categories were:

1. insights into career and life after graduation

2. conduct of the class

3. the Professor's passion, empathy, and clarity of communication

4. course subject content instruction

The following Table 3 shows a ranking of responses; Figure 2 shows the distribution of responses:

Table 3. Student Expectations of Professor for a Great Class

\begin{tabular}{l|c|c}
\hline \multicolumn{1}{c}{ Student Expectations of Professor } & Number & Percent \\
\hline Career and life after graduation & 26 & $32 \%$ \\
\hline Conduct of the class & 25 & 30 \\
\hline Professor's passion, empathy, and communication & 21 & 26 \\
\hline Course subject content instruction & 10 & 12 \\
\hline Total & 82 & $100 \%$ \\
\hline
\end{tabular}

Source: Responses by students in the course. 
Selected comments within the designated student expectation categories were:

- Career and life after graduation. Students were in accord in expressing their desire for real-world, reallife input with 22 of 26 responses emphasizing this expectation of the Professor.

- Conduct of the class. Students focused on desires for time efficiency, clear communication about factors affecting grades, access to extra help, and accommodations by the Professor. Several students wanted an engaging classroom experience.

- Professor's passion, empathy, and communication. Over half of the mentions showed the desire for a productive relationship between students and Professor. These were expressed as empathy, trust, honest feedback, respect, understanding students' priorities, and being available to students. Students wanted their Professor to be enthusiastic about teaching and to care the students and their success.

- Course subject content instruction. Only $12 \%$ of comments related to content. Those comments clustered around covering the subject, learning the basics, and understanding concepts.

Figure 2. Student expectations for a great class.

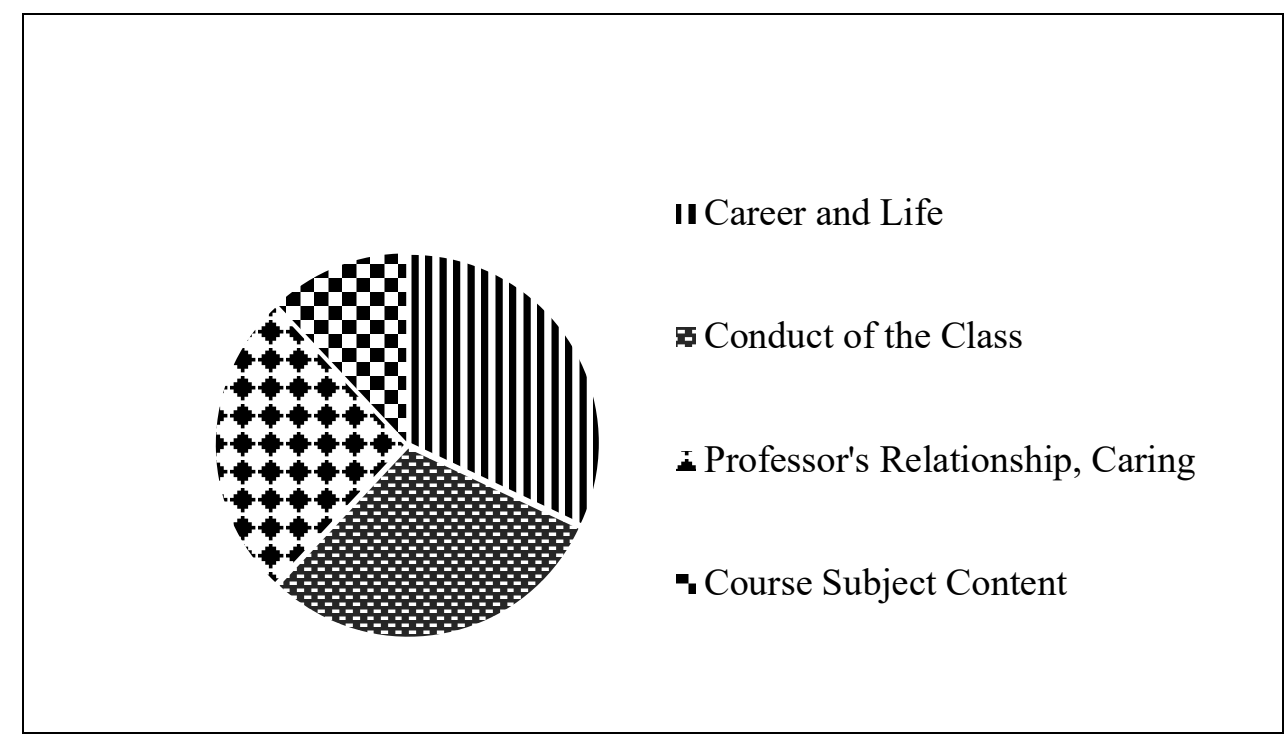

\section{Student Ratings of Factors Critical to Managerial Effectiveness}

The pre- and post- surveys completed by the students enrolled in the course were administered in the 3rd and 12th weeks (4th and 22nd class meetings) of the semester. Question 1 requested the students to rate each of 13 factors critical to management effectiveness, as listed in Table 4 . The 13 factors represent a synthesis of competencies identified by studies based on employers' responses regarding work readiness of college graduates (Council for Adult and Experiential Learning, 2011; Hora, 2017; National Association of Colleges and Employers, n.d.; Ritter et al. 2018).

Responses were collected using a 5-point scale with the following response choices related to degree of being critical to effective management: not at all; probably not; somewhat; probably; definitely. Table 4 summarizes student ratings, which are also depicted in Figure 3. 
The end of course ranking of factors by students showed the top 3 as:

1. communicate effectively

2. cultivate a positive culture

3. lead by example

Table 4. Student Ratings of Importance of Mangerial Actions Critical to Effectiveness (Q1)

\begin{tabular}{|c|c|c|c|c|c|c|}
\hline \multirow{3}{*}{ Management Effectiveness Factor } & \multicolumn{6}{|c|}{ Student Ratings of “5” (High) } \\
\hline & \multicolumn{3}{|c|}{ Beginning of Course } & \multicolumn{3}{|c|}{ End of Course } \\
\hline & Rank & $\begin{array}{c}\text { Number } \\
(\mathbf{N}=33)\end{array}$ & Percent & Rank & $\begin{array}{c}\text { Number } \\
(\mathrm{N}-35)\end{array}$ & Percent \\
\hline Communicate effectively & 1 & 31 & $94 \%$ & 1 & 35 & $100 \%$ \\
\hline Cultivate a positive culture & 4 & 28 & 85 & 2 & 33 & 94 \\
\hline Lead by example & 5 & 28 & 76 & 3 & 31 & 89 \\
\hline Accept responsibility & 2 & 29 & 88 & 4 & 31 & 89 \\
\hline Treat employees fairly & 3 & 29 & 88 & 5 & 30 & 86 \\
\hline Build unity of purpose & 8 & 22 & 67 & 6 & 29 & 83 \\
\hline Keep focus on goals & 10 & 22 & 67 & 7 & 29 & 83 \\
\hline Organize and plan & 6 & 25 & 76 & 8 & 29 & 83 \\
\hline Share vision & 11 & 20 & 61 & 9 & 27 & 77 \\
\hline Initiate actions to achieve goals & 9 & 22 & 67 & 10 & 27 & 77 \\
\hline Connect with employers & 12 & 20 & 61 & 11 & 27 & 77 \\
\hline Invite input and feedback & 7 & 25 & 76 & 12 & 27 & 77 \\
\hline Understand operating issues & 13 & 14 & 42 & 13 & 23 & 66 \\
\hline
\end{tabular}

Source: Student survey responses.

Figure 3. Ratings of importance of managerial actions. Source: Student survey responses.

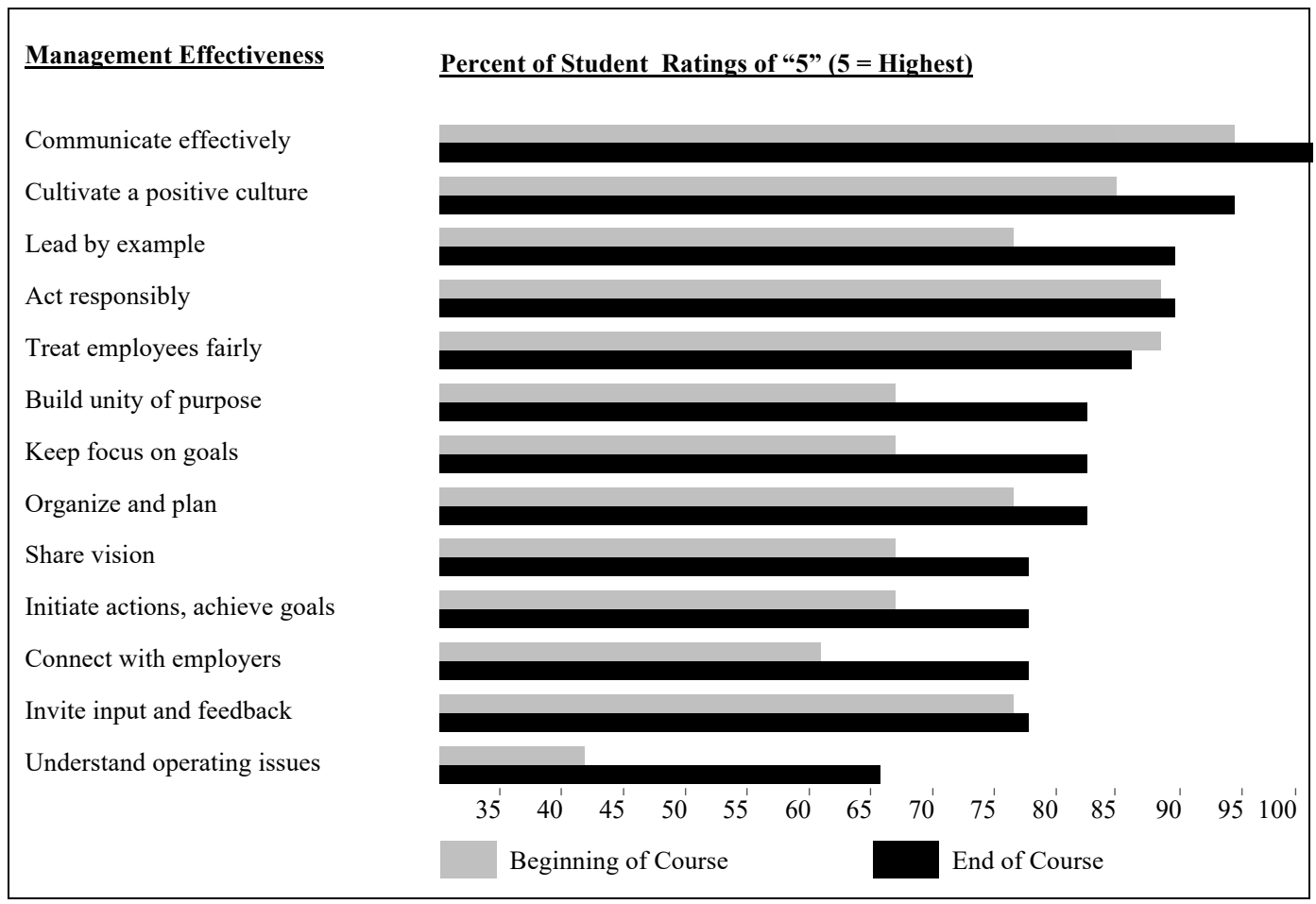


Combining the 13 management effectiveness factors and calculating mean scores showed the pre-post survey difference to be statistically significant at the .05 level using the one-tailed $t$-test, indicating the increased importance of the effectiveness factors, according to the students, from beginning to the end of the course, as shown in Table 5.

Table 5. Management Effectiveness - Mean Ratings (Q1)

\begin{tabular}{l|c|c}
\hline \multicolumn{1}{c|}{ Combined Effectiveness Factors } & Beginning of Course & End of Course \\
\hline Communicate effectively & & \\
\hline Cultivate a positive culture & & \\
\hline Lead by example & & \\
\hline Accept responsibility & & \\
\hline Treat employees fairly & & \\
\hline Build unity of purpose & & \\
\hline Keep focus on goals & & \\
\hline Organize and plan & & \\
\hline Share vision & & \\
\hline Initiate actions to achieve goals & & \\
\hline Connect with employers & & \\
\hline Invite input and feedback & & \\
\hline Understand operating issues & & \\
\hline Significant, one tailed $t$-test & - & \\
\hline Standard Deviation & & \\
\hline $\mathrm{N}=$ & & \\
\hline
\end{tabular}

Source: Student survey responses.

\section{Soft Skills: Importance Versus Confidence in Performing in Career Roles}

In contrast to Question 1, which focused on the importance of overall management effectiveness, Questions 2 and 3 of the pre-post surveys collected student ratings related to soft skills proficiency expected of college graduates by employers as reported in research findings (Brink \& Costigan, 2015; U.S. Chamber of Commerce Foundation, 2017; Youth Power, 2017). Students rated 6 soft skills, as shown in the following list. The description to the right of each soft skill topic was provided to assure common understanding among the student respondents.

- Proactive, goal driven: Take charge, self-motivated, decisive, assertive, "can-do" attitude, enthusiastic, complete tasks

- Analytical/critical thinking: Conceptual thinker, creative insight, recognize and define problems, link ideas, systematic, offer practical intelligence, propose solutions

- Mastery of productivity skills: Organize, plan, manage time, expert in written and oral communication, work efficiently and effectively

- Management of self: Self-aware, self-disciplined, maintain self-control

- Interpersonal skills: Establish rapport, collaborate, network, influence others, empathic and aware of others' feelings

- Team contributor, builder: Resolve conflicts, motivate others, create positive group dynamics, listen, influence others, support group members

The pre- and post-survey Questions 2 and 3 requested students to rate their soft-skill proficiencies using 5 point scales. Question 2 instructed students to rate factors on importance to effectiveness in performing the student's role after completing college. Choices were:

1. among my lowest priorities

2. could be important

3. probably important

4. definitely important

5. among my highest priorities 
Question 3 instructed students to rate their confidence in performing their role after completing college on the same factors as Question 2. Choices for students to rate their confidence were:

1. not at all confident

2. slightly confident

3. somewhat confident

4. tentatively confident

5. definitely confident

Comparison of pre- and post-ratings on importance of proficiencies indicated no difference, with means of 4.62 and 4.61, respectively. Comparison of pre- and post-ratings on student confidence also showed no difference, with means of 4.28 and 4.29, respectively. The higher ratings on importance compared to the lower ratings on confidence are interpreted to indicate that students recognize their need to continue to develop their soft skills. In the post-test, in addition to the ratings, students were requested to answer the question "In what ways has your confidence related to (each of the 6 proficiency factors) changed due to what you have learned in this course?

The following responses provide insight into the more fully developed perceptions by students at the end of the 12 week course:

\section{Proactive, Goal Driven}

- Now have clear steps on how to be organized Confidence dictates how I am going to achieve my goals

- Class has taught me to be self-motivated in my interpersonal relationships

- My enthusiasm/attitude has improved

- We have learned the ins and outs of self-efficacy

- I feel like I am more confident.

\section{Analytical/Critical Thinking}

- I have learned better ways to propose solutions

- The articles caused me to think critically

- The exams require drawing sometimes-hidden connections, strengthening critical thinking

- My critical thinking skills are more developed

- My analytical skills have improved tremendously

\section{Mastery of Productivity Skills}

- I utilize the resources around me better

- I'm more confident in how I plan for my life

- Through the tests I have learned to be more efficient

- I have learned how to better manage my time

- Know how to be more organized/efficient

\section{Management of Self}

- Confidence in what controls self-management

- To reflect and know personal goals in my life

- Taking care of yourself is important

- Learned the importance of self-management

- The key to management is being self-aware 


\section{Interpersonal Skills}

- Know how to connect and appreciate others

- Communication is key to performance and efficiency

- This was the biggest learning: Human capital and others

- Need to take time for people and establish genuine trust

- Connecting with people, understanding them

\section{Team Contributor, Builder}

- Learned some great methods to help unite and motivate teams

- It's how we approach problems that makes a great team

- Learned to build up others and contribute to a team

- I am aware of the importance of teams and diversity

- It is essential to listen to others and understand who they are

\section{4 x 6 Inch Cards: Most Important Management Learning from Class Today}

Student responses completed on 4 x 6-inch cards at each class answered the question "What was the most important management learning from class today?" Responses were grouped into subject categories and analyzed. The top four subjects were:
1. leadership
2. understanding human behavior
3. human resources, which included diversity
4. team performance

The 3 lowest ranked subjects were:

1. global management (lowest)

2. organization structure (second lowest)

3. decision making (third lowest)

The subject rankings are presented in the following Table 6 .

Table 6. Most Important Management Learning from Class Today

\begin{tabular}{|c|c|c|c|c|}
\hline \multirow[b]{2}{*}{$\begin{array}{l}\text { Chapter } \\
\text { Number }\end{array}$} & \multirow[b]{2}{*}{ Chapter Subject } & \multicolumn{3}{|c|}{ Textbook Chapter Mentions } \\
\hline & & $\begin{array}{c}\text { Ranking of } \\
\text { Mentions }\end{array}$ & $\begin{array}{l}\text { Number of } \\
\text { Mentions }\end{array}$ & $\begin{array}{c}\text { Percent of } \\
\text { Total }\end{array}$ \\
\hline 1 & Managing in a Changing World & 9 & 32 & $4.4 \%$ \\
\hline 2 & Environment, Culture & 10 & 32 & 4.4 \\
\hline 3 & Global Management & 14 & 7 & 1.0 \\
\hline 4 & Ethics, Social Responsibility & 5 & 63 & 8.6 \\
\hline 5 & Planning, Strategy, Goal Setting & 6 & 47 & 6.4 \\
\hline 6 & Managerial Decision Making & 12 & 25 & 3.4 \\
\hline 7 & Organization Structure, Adapting & 13 & 20 & 2.7 \\
\hline 8 & Change, Innovation & 11 & 26 & 3.5 \\
\hline 9 & Human Resources, Diversity & 3 & 84 & 11.4 \\
\hline 10 & Understanding Human Behavior & 2 & 120 & 16.3 \\
\hline 11 & Leadership & 1 & 129 & 17.5 \\
\hline 12 & Motivating Employees & 7 & 34 & 4.6 \\
\hline 13 & Communication & 8 & 33 & 4.5 \\
\hline \multirow[t]{2}{*}{14} & Team Performance & 4 & 83 & 11.3 \\
\hline & Total & -- & 735 & $100.0 \%$ \\
\hline
\end{tabular}

Source: Student survey responses. 
In addition to acting as a learning reinforcement, the responses yielded perspective on new incremental learning, insights gained by students, counter-intuitive outcomes, unexpected contradictions to formerly held assumptions, and recent research that informed students of findings not yet commonly held. Following are student comments related to the top-ranked subjects:

\section{Leadership}

- Always make time for people. Care about employees. Get to know them and their motivations

- Be with employees, not separate from them

- Leaders need to invest in their employees' success A leader has to communicate values

- Influence is more important than power

- A leader needs to be connected to a transcendent purpose

\section{Understanding Human Behavior}

- Integrate personally and professionally

- Leadership is closely linked to being authentic

- We can never choose what comes our way, but we can choose how to respond. Need to be adaptable

- More important to manage energy than time

- Understand yourself and others as well as emotions. Be self-aware

- We can't manage others if we can't management ourselves.

- Autonomy increases employee engagement and improves results

\section{Human Resources, Diversity}

- Most important thing for an employee is how they are treated. Need to be treated fairly and equally

- The higher the diversity, the better the results. Diversity increases innovation and creativity

- Teams with more women outperform teams with more men. Companies with women in senior-level positions outperform companies with no women in senior-level positions

- Develop and define jobs so employees can use their full potential

- Human capital is key. Employees are assets.

\section{Team Performance}

- Leaderless teams rely on self-management and autonomy

- Leaderless teams deliver quick, powerful results

- Results achieved with other people will be fresh, practical, and solution-focused

- Teams composed of a variety of skills and knowledge help a company to adapt

- Team members need to trust each other and care for each other

- Teams perform better when members connect personally and professionally

In addition to subjects related to the course content, students pulled advice from their course experience to carry into their after-college job searches and after-employment careers. Examples of these points are:

\section{Job Search and Career Advice}

- Be able to tell someone in 15 seconds who you are. Otherwise the opportunity is gone

- Thinking and acting quickly is normal. Learn to do it!

- On a resume use the terms "curious" and "solution-focused"

- During an interview say you want to contribute to the successful implementation of the organization's strategy

- Do not settle. Go for what you want. Employees will regret it if they are not a good fit

- Ask for new responsibilities related to the organization's strategy

- Surround yourself with successful people to be successful 


\section{Most Important Aspects of Management to Learn (Have Learned); Data from Post-Survey}

In the course pre- and post-survey the question was inserted, "The 3 aspects of management (post: I have learned) that will be (have been) most important for me to learn in this course to improve my management effectiveness:"

$1 \ldots ; 2$

Table 7 shows the ranking of responses at the beginning and end of the course. The three management aspects that showed the most increase from beginning to end of course in rank order were:

1. caring, authenticity, openness, confidence

2. organizing, planning, goal setting

3. human capital, human resources

The two aspects that declined in rank were (a) critical thinking, critical analysis and (b) leadership, team performance.

Table 7. Student Ratings of Most Important Aspects of Management to Learn (Have Learned) at Beginning and End of Course

\begin{tabular}{l|c|c|c|c}
\hline \multirow{2}{*}{ Most Important Management Aspect } & \multicolumn{2}{c|}{ Number of Mentions } & \multicolumn{2}{c}{ Change } \\
\cline { 2 - 5 } & Beginning of Course & End of Course & Number & Percent \\
\hline Self-management, reflection, ethics & 25 & 28 & 3 & $12 \%$ \\
\hline Interpersonal skills, communication & 20 & 21 & -1 & 5 \\
\hline Leadership, team performance & 19 & 18 & 0 & --5 \\
\hline Organization culture, diversity & 10 & 10 & --8 & --900 \\
\hline Critical thinking, critical analysis & 9 & 1 & 5 & 83 \\
\hline Organizing, planning, goal setting & 6 & 11 & 6 & 220 \\
\hline Caring, authenticity, openness, confidence & 5 & 5 & 4 & 500 \\
\hline Human capital, human resources & 1 & 89 & -- & -- \\
\hline Total & 89 & & & - \\
\hline Souncy
\end{tabular}

Source: Student survey responses.

\section{Most and Least Engaging Class Time Activities, Data from Post-Survey}

Two additional questions in post-survey covered student engagement. The questions were: The activities that took place during class that (a) engaged me the most and (b) that I found least engaging are: Space of one line following each question was provided for student responses. Table 8 lists the most liked activities of the class, to which 42 responses were made including responses that covered more than one activity. Highest rankings were the Professor's stories and articles distributed at class meetings and integrated into exams. As shown in Table 8, only 22 responses were received related to least liked activities, with the text and the lectures topping that list. The drop in responses from most liked to least liked is attributed to the students' generally positive experience with the course and is consistent with student responses in the Seaver College end-of-course evaluations presented in the following section.

Table 8. Most and Least Engaging Class Time Activities

\begin{tabular}{l|c|c|c|c|c}
\hline \multicolumn{1}{|c|}{ Most Liked (s) } & Number & Percent & Least Liked & Number & Percent \\
\hline Stories & 20 & $48 \%$ & Text & 15 & $68 \%$ \\
\hline Articles & 7 & 16 & Lecture & 4 & 18 \\
\hline Exams & 4 & 10 & Articles & 2 & 9 \\
\hline Specific topics & 4 & 10 & Stories & 1 & 5 \\
\hline Text, study guide & 3 & 7 & & & \\
\hline Lectures & 2 & 5 & & & \\
\hline Diagrams & 1 & 2 & & & \\
\hline Cards filled out (today's learning) & 1 & 2 & & & \\
\hline Total & 42 & $100 \%$ & & & $100 \%$ \\
\hline
\end{tabular}

Source: Student survey responses. 


\section{Responses to Survey by Seaver College: Evaluations by Students}

The student response rate to the Seaver College course evaluation survey was high, with 33 of 36 students responding. As shown in Table 9, median ratings were between 4 and 5, except for two class sections that gave mean ratings of 3.81 and 3.44, respectively to the factor "demanding in comparison to other courses."

Students gave high ratings to the course, class experience, and Professor. Following are abbreviated excerpts from the student comments:

\section{Course Questions}

- Professor has a clear, direct plan. Is clear about expectations. Adapts based on what is best for students

- Lecture and study guide follow the textbook

- Exams really make you think

- Blown away by how much I learn

- Every student gains knowledge and understanding they will use for the rest of their lives

- Professor leads with a distinct purpose, manages himself, and manages the class to illustrate management

- Every exam has an article to read and link to key topics, which has trained me to think critically

- Professor's detailed outline of what will be covered in class is helpful

Table 9. Evaluations by Students: Management Theory \& Practice, Fall 2017. Ratings by Students in Class Sections 352.01 and 352.02

\begin{tabular}{|c|c|c|c|c|}
\hline \multirow[b]{2}{*}{ Evaluation Factor } & \multicolumn{2}{|c|}{ Section $352.01(n=17)$} & \multicolumn{2}{|c|}{ Section $352.02(n=16)$} \\
\hline & $\begin{array}{c}\text { Mean } \\
\text { Ratings }\end{array}$ & $\begin{array}{l}\text { Median } \\
\text { Ratings }\end{array}$ & $\begin{array}{l}\text { Mean } \\
\text { Ratings }\end{array}$ & $\begin{array}{l}\text { Median } \\
\text { Ratings }\end{array}$ \\
\hline \multicolumn{5}{|l|}{ Course Questions } \\
\hline Well organized & 4.00 & 4 & 4.75 & 5 \\
\hline Textbook and other reading assignments are appropriate in content & 4.31 & 5 & 4.75 & 5 \\
\hline Tests and other evaluations are appropriate in content and difficulty & 3.88 & 4 & 4.38 & 4.5 \\
\hline Assignments are reasonable and appropriate in content and difficulty & 4.25 & 4 & 4.56 & 5 \\
\hline Demanding in comparison to other courses & 3.81 & 4 & 3.44 & 3 \\
\hline Increased my knowledge or understanding of the subject & 4.63 & 5 & 4.69 & 5 \\
\hline Is excellent & 4.13 & 4.5 & 4.63 & 5 \\
\hline \multicolumn{5}{|l|}{ Overall Class Experience } \\
\hline $\begin{array}{l}\text { Enhanced my ability to think clearly, logically, independently, and } \\
\text { critically }\end{array}$ & 4.18 & 4 & 4.69 & 5 \\
\hline $\begin{array}{l}\text { Contributed to the development of my sense of personal values and } \\
\text { moral integrity }\end{array}$ & 4.41 & 5 & 4.75 & 5 \\
\hline \multicolumn{5}{|l|}{ Evaluation Factors-Instructor } \\
\hline Shows interest and enthusiasm for teaching the course & 4.65 & 5 & 5.00 & 5 \\
\hline Is available outside of class for consultation if needed & 4.65 & 5 & 5.00 & 5 \\
\hline Is prepared for class and makes good use of class time & 4.12 & 5 & 4.69 & 5 \\
\hline Presents course material in a clear and engaging manner & 3.82 & 4 & 4.63 & 5 \\
\hline Is an excellent teacher & 4.13 & 4.5 & 4.69 & 5 \\
\hline
\end{tabular}

Note: Ratings made by students on a 5 point scale with 5 high.

Source: Pepperdine University, Seaver College Business Division, Course Evaluation Survey, Fall 2017.

\section{Class Experience}

- Professor thinks of topics and examples that directly relate to the content and real life

- Class made me think about my ethic and what I want to value/highlight in my life

- Real-world examples of concepts we learn in class

- Professor knows this course from an insider business perspective

- Professor is excited about teaching and makes me want to come to class at 8am. 
Evaluation of Instructor

- Takes time to get to know people

- Makes me want to be a better person

- How to be a better human, therefore a better manager

- Shows genuine excitement over the material

- Passionate about the subject matter; really knows what he is talking about

- Accommodating and willing to help at any time

- Makes himself available to his students at all times

- Professor is caring. He goes above and above and beyond for his students

- Taught me how to be a professional in business and how to be a better human being

- Mindset is students come first

- Always patient and understanding

Of the 33 students who completed the survey, $23(70 \%)$ did not offer a response to the question, "What suggestions do you have for improving the course and how it is taught?" The 10 who responded suggested more class interaction. Evidence also surfaced related to frustration with the lecture format and the need for more active student participation:

\section{Change Suggestions}

- Not the biggest fan of a Professor just lecturing the group

- Professor should engage the students rather than just talk at them

- More facilitation among students

- To fit the metaphor of classroom like an organization, students need to be more involved with the material and each other.

\section{CONCLUSIONS AND RECOMMENDATIONS}

The lecture class, a fixture of higher education at undergraduate and graduate levels, is presented across the range of small class sizes and large lecture halls. Rival instructional formats now provide expanded instructional choices, new delivery methods, and ways of receiving and processing information preferred by students and the adult public. Indications concerning the future of the lecture method point to its gradual evolution in scope and form. This article presents the experience of enriching a lecture course and improving engagement by: (a) focusing on students' needs in the course design and delivery; (b) gathering frequent input from students regarding their preferences, (c) integrating career information beyond the text book, and (d) assigning tasks that required students to look beyond school toward their transition into the workforce.

The students expressed their satisfaction with the course in laudatory terms. Analysis of student responses to questionnaires and open-ended questions provided useful insights. The following summary is offered to assist others faced with the knowledge that changes need to be implemented and student engagement needs to be a priority. This roadmap can help achieve productive outcomes:

- Listen to the students intently and frequently throughout the course, and through a variety of means that offer input. Hear the students' voices

- Track student responses, perhaps this week versus last week, or compared with last semester and last year

- Establish and share with students a clear agenda and focused objectives for each class meeting. Be well organized and keep the class structure consistent unless variation is justified

- Devise a feedback process for quick analysis of responses that detect changes. Look for hints that students want change. Build in flexibility around class schedules and content to enable making adjustments

- Break up lectures of more than 15 minutes into segments interspersed with student engagement activities, for example, 10 minutes of student participation in duos or small teams to create approaches to solving a dilemma related to the day's subject

- As practical, share ownership of the class with students; empower students by offering choices such as 
day of exams or even delay of exams by a class meeting or two

- Recognize that a Professor is an authority figure and models behavior of a manager or professional in the environment students plan to enter. Be enthusiastic about the course subject and the opportunity to add to students' capabilities

- In teaching style, project authenticity, transparency, openness, and availability to students when needed to assist with their progress. Allot time to get to know students and their concerns

- Employ explicit ways to convey caring for students, followed up by concrete and consistent demonstrations of caring that solidify relationships of trust

- Supplement course textbook content with resources that inspire, motivate, and offer insight into real world successes and challenges

- Integrate into class assignments content and tasks to improve proficiency and confidence in using students' workplace competencies

- Stay current with news, trends, and developments related to student learning experiences across media andeducational choices available to students. Stay alert to changes in student priorities and mindsets that can suggest ways to improve student engagement

- Encourage support from school administrations for professional development, including using digital technologies, understanding communication media, practicing in video facilities, and coaching in public speaking

- Cooperate in cross-departmental and student support programs that assist students in school-to-career transitioning including working with College Career Placement services

\section{AUTHOR BIOGRAPHY}

William W. Arnold is a Professor in the Business Division of Seaver College, Pepperdine University, Malibu, California, where he teaches Management Theory and Practice, Business Strategy, and Servant Leadership. Dr. Arnold held executive positions with several major health systems where he led revitalization and turnaround. A champion of authenticity in leadership, Dr. Arnold presented his experiences in The Human Touch. In engaging with students he illustrates business principles by drawing on examples from his career. Dr. Arnold holds Doctor's, Master's, and Bachelor's degrees, respectively, from Pepperdine University; University of California, Los Angeles; and the University of Washington.

\section{REFERENCES}

Barnes \& Noble College (2015). The college student mindset for career preparation and success. Retrieved from https://next.bncollege.com/wp-content/uploads/2015/01/Millennial-Survey-Report_FINAL914.pdf

Belkin, D. (2017, June 6). Many colleges fail in teaching how to think. Wall Street Journal. Retrieved from https:/www.wsj.com/articles/exclusive-test-data-many-colleges-fail-to-improve-critical-thinking-skills-1496686662

Bledow, R., Carette, B., Kuehnel, J., \& Blister, D. (2017). Learning from others' failures: The effectiveness of failure stories for managerial learning. Academy of Learning and Education, 16(1), 39-53. Retrieved from https://ink.library.smu.edu.sg/cgi/viewcontent.cgi?article=1021\&context=lkcsb_research_all

Brink, K. E., \& Costigan, R. D. (2015). Oral communication skills: Are the priorities of the workplace and AACSB- accredited business programs aligned? Retrieved from https://journals.aom.org/doi/10.5465/amle.2013.0044

Bryant, A. (2016, April 2). Interview with Dottie Mattison “Talk less but ask “why' more.” New York Times, BU2.

Cajiao, J., \& Burke, M. (2016). How instructional methods influence skill development in management education. Academy of Management Learning \& Education, 15(3), 508-524. http://dx.doi.org/10.5465/amle.2013.0354

Cappelli, P., \& Tavis, A. (2018, March). HR goes agile. Harvard Business Review, 47-53.

Carr, N. (2017, October 7). How smart phones hijack our minds. Wall Street Journal, Review section, p. C1-2.

Charlton, B. G. (2006). Lectures are an effective teaching method because they exploit human evolved 'human nature' to improve learning. Medical Hypotheses, 67, 1261, 5. Retrieved from https://www.hedweb.com/bgcharlton/ed-lect.html

Council for Adult and Experiential Learning (CAEL). (2011). Common skills for employability and pathways to advancement user guide. Retrieved from https://cdn2.hubspot.net/hubfs/617695/Walmart\%20competency\%20mapping/CAEL\%20Competency\%20Mapping\%2 0User\%20Guide\%2011.16.17.pdf?hssc=259760725.4.1531270405702\&stc=259760725.4f9a02410852904ee00a75a 84 4acaad7.1531270405702.1531270405702.1531270405702.1\&_hsfp=2673893155\&hsCtaTracking=c3bb914c-0d05441f-be40-01ee96c85a34\%7C318b305c-6fb6-4b10-a9f6-4cbd93e126b1

Creswell, J. W. (2014). Research design: Qualitative, quantitative, and mixed method approaches (4 ${ }^{\text {th }}$ ed.). Thousand Oaks, CA: 
Sage Publications.

Daft, R. L., \& Marcic, D. (2015) Understanding management $\left(9^{\text {th }}\right.$ ed). Stamford CT: Cengage Learning.

Durant, R. A.; Carlon, D. M.; \& Downs, A. (2017). The efficiency challenge: Creating a transformative learning experience in a principles of management course. Journal of Management Education, 41(6), 852-872. Abstract retrieved from https://eric.ed.gov/?id=EJ1157706

Fernandez-Araoz, F., Roscoe, A., \& Aramaki, K. (2017, November) Turning potential into success: The missing link in leadership development. Harvard Business Review, 87-93.

Florida Atlantic University College of Business. (n.d.). How millennials are changing business schools for the better. Retrieved from https://business.fau.edu/masters-phd/mba-program/stories/how-millennials-are-changing-business-schools-forthe-better/index.php

Fry, R. (2018). Millennials are the largest generation in the U.S. labor force. Retrieved from http://www.pewresearch.org/facttank/2018/04/11/millennials-largest-generation-us-labor-force/

Gaertner, M. N., Conley, D. T., Stoltz, P. G. (2016). Redefining readiness in education and the workplace. Pearson Education. Retrieved from https:/www.pearson.com/us/higher-education/why-choose-pearson/thought- leadership/careerreadiness-employability/research-white-papers.html

Gehlbach, H., \& Brinkworth, M. E. (2011). Measure twice, cut down error: A process for enhancing the validity of survey scales. Review of General Psychology, 15(4), 380-387

Graduate Management Admission Council. (2016, July 7). Are soft skills teachable? Retrieved from https://www.gmac.com/market-intelligence-and-research/research-insights/b-school-outcomes/are-soft- skills-teachable

Gross-Loh, C. (2016). Should colleges really eliminate the college lecture? Retrieved from https://www.theatlantic.com/education/archive/w016/07/eliminating the lecture/491135/

Heath, C., \& Heath, D. (2008). Made to Stick: Why some ideas survive and others die. New York, NY: Random House, pp. 19-21

Hora, M. (2017). Beyond the skills gap: Preparing college students for life and work. NACE Journal. Retrieved from http://www.naceweb.org/career-readiness/trends-and-predictions/beyond-the-skills-gap/

Jaschik, S. (2015). Well-prepared in their own eyes. Retrieved from https://www.insidehighered.com/news/2015/01/20/studyfinds-big-gaps-between-student-and-employer-perceptions

Jaschik, S. (2018). Lecture instruction: Alive and not so well. Retrieved from https://www.insidehighered.com/news/2018/04/02/study-finds-lecture-remains-dominant-form-teaching-stem

Johnson, J. (2016). The importance of career readiness and authentic business engagement. Center for Education and Workforce, U.S. Chamber of Commerce Foundation. Retrieved from https:www.uschamberfoundation.org/blog/post/importancecareer-readiness-and-authentic-business-engagement

Lang, J.M. (2016). Small changes in teaching: The first 5 minutes of class: 4 quick ways to shift students' attention from life's distractions to your course content. Retrieved from https://www.chronicle.com/article/Small- Changes-in-TeachingThe/234869? cid=wcontentgrid_hp_13

McCracken, H. (2017). Nadella rewrites Microsoft's code. Fast Company.com. Retrieved from https://www.fastcompany.com/40457458/satya-nadella-rewrites-microsofts-code

National Association of Colleges and Employers (NACE). (n.d.). Career readiness for the new college graduate: A definition and competencies. Retrieved from http://www.naceweb.org/career-readiness/competencies/career-readiness-defined/

National Association of Colleges and Employers (NACE). (2018a). Are college graduates "career ready"? Retrieved from http://www.naceweb.org/career-readiness/competencies/are-college-graduates-career-ready/

National Association of Colleges and Employers (NACE). (2018b). First 90 days: Congratulations, you got the job! Now What? Retrieved from http://www.naceweb.org/career-development/best-practices/program-preps- students-for-the-first-90days-on-the-job/

Panorama Education. (2015). User Guide: Panorama Student Survey. Available from www.panoramaed.com/panorama-studentsurvey

Pedersen, C. L. (2018, Summer). Managing the distraction-focus paradox. MIT Sloan Management Review. Retrieved from https:/sloanreview.mit.edu/article/managing-the-distraction-focus-paradox/

Pepperdine University (2017). Pepperdine Seaver College of Letters, Arts, and Sciences 2017-2018 Academic Catalog, p. 136. Retrieved from https:/seaver.pepperdine.edu/academics/content/2017seavercatalog.pdf

Reed, L. (2018). Building critical thinking skills to solve problems at work. Retrieved from https://www.business.com/articles/building-critical-thinking-skills-at-work/

Ritter, B. A., Small, E. E., Mortimer, J. W., \& Doll, J. L. (2018). Designing management curriculum for workplace readiness: Developing students' soft skills. Journal of Management Education, 42(1), 80-103. Abstract retrieved from http://journals.sagepub.com/doi/abs/10.1177/1052562917703679

Shellenbarger, S. (2014, January 15). Career Makeover: Shaking off a shy image. Wall Street Journal. Work and Family Section. Retrieved from https://www.wsj.com/articles/shaking-off-a-shy-reputation-at-work- 1389742837

Shih, L. (2017). Career readiness: Equipping students for the workplace of today and tomorrow. Excelsior College. https://life.excelsior.edu/career-readiness-equipping-students-workplace-today-tomorrow/

Thibodeaux, W. (2018). Top CEOs say these are 8 habits you need to ditch if you want to be successful. Innovate. Retrieved from https://www.inc.com/wanda-thibodeaux/top-ceos-say-these-are-8-habits-you-need-to-ditch- if-you-want-to-be- 
successful.html

U.S. Chamber of Commerce Foundation. (2017). Bridging the Soft Skills Gap: How the business and education centers are partnering to prepare students for $21^{\text {st }}$ century workforce. https://www.uschamberfoundation.org/reports/soft-skills-gap

What the best managers do to develop their employees today. (2018, May). Harvard Business Review, 22-24. Retrieved from https://hbr.org/2018/05/managers-cant-be-great-coaches-all-by-themselves

Williams, A. (2015), Sept. 18). Move over millennials, here comes generation Z. New York Times. Retrieved from https://www.nytimes.com/2015/09/20/fashion/move-over-millennials-here-comes-generation-z.html

Youth Power (2017). Guiding principles for building soft skills among adolescents and young adults. Retrieved from http://www.youthpower.org/resources/guiding-principles-building-soft-and-life-skills-among-adolescents- and-youngadults 